\title{
Research on Online Teaching Effectiveness and Strategies for Improving Teaching Quality -- Based on Data Analysis of Universities in Yunnan Province
}

\author{
Yue Yang* \\ Yunnan University of Finance and Economics, Kunming, Yunnan, China \\ *Corresponding author. Email: yy14207@126.com
}

\begin{abstract}
Through the survey of online teaching situation of university teachers and students, we mainly investigate the students' understanding of online teaching, their feelings of using online teaching and the problems they encountered in the process of using online teaching, in order to get a more comprehensive understanding of the actual development of online teaching, 882 valid questionnaires were collected. The survey results show that the main problems of online teaching are, on the one hand, the difficulty of communication and interaction between teachers and students, and, on the other hand, the dampening of teachers' and students' enthusiasm and other problems. This paper proposes three ways to improve the quality of online teaching based on actual research results. First, teachers should improve the regular grade and attendance checking system and be good at discovering other functions of online teaching. Second, students' participation in online teaching should be enhanced and online teaching should be combined with other learning platforms. Third, students should have a clear learning task and strengthen the communication with teachers.
\end{abstract}

Keywords: Online teaching, Institutions of higher education, Way.

\section{INTRODUCTION}

In 2020, according to the needs of epidemic prevention and control, 1,454 colleges and universities nationwide carried out online teaching, 1.03 million teachers offered 1.07 million courses online, with 12.26 million courses in total, and a total of 17.75 million college students participated in online learning. The scale, scope and depth of this online teaching are unprecedented in the history of higher education in the world and the first experiment in the world. It not only successfully coped with the crisis of school suspension, teaching suspension and class suspension brought by the epidemic, but also created a new peak of online teaching in practice, explored a new practice of online teaching and formed a new paradigm of online teaching, which is of great significance to the future reform and innovative development of higher education in China and the world.

\section{STATUS OF ONLINE TEACHING RESEARCH}

Online teaching also refers to online education. The current concept generally refers to a kind of network-based learning behavior, through which learners and teachers can carry out teaching activities no matter the distance between them. In addition, with the help of online teaching support resources such as online courseware, students can learn anytime and anywhere, which really breaks the limitation of time and space.

For the improvement of online teaching quality, domestic scholar Fang Lin (2018) proposed that "Internet + college education" is bound to appear as a new business model that can play the role of optimization of the Internet in the allocation of college education resources. Xie Huomu et al. (2020) mentioned that by closely combining online teaching with offline classroom, colleges and universities should shift from passive implementation to active promotion of curriculum reform and classroom revolution. Zeng Liwen (2020) argued that universities should optimize the existing teaching platform, strengthen the training of teachers' teaching design and teaching skills, and improve the supervisiory mechanism of online teaching in combination with the actual situation of our university. Jiao Jianli et al. (2020) suggested that many places have inadequate training for teachers and 
measures need to be strengthened.

\section{ONLINE TEACHING RESEARCH DATA}

Since the promotion of online education, online teaching has faced challenges from various groups, students, teachers and other related groups need to be more fully prepared for online teaching. It is a great challenge for teachers to carry out targeted training and for students to be guided to learn independently. The research questionnaires were distributed to students in three universities in Yunnan Province, and 882 valid questionnaires were collected, with an efficiency rate of $85 \%$. The questionnaires focused on issues such as the length of students' study, students' understanding and recognition of online teaching, and students' feelings of using online teaching etc.

\subsection{The Number of Students Covered and the Length of Study}

The research focused on a total of 882 undergraduates, mainly focusing on freshmen, sophomores and juniors. Freshman students accounted for $40.49 \%$, sophomores accounted for $33.27 \%$, juniors accounted for $23.76 \%$, and seniors accounted for only $2.48 \%$. Among them, according to the curriculum, the freshman year has the most courses, so there are the most students participating.

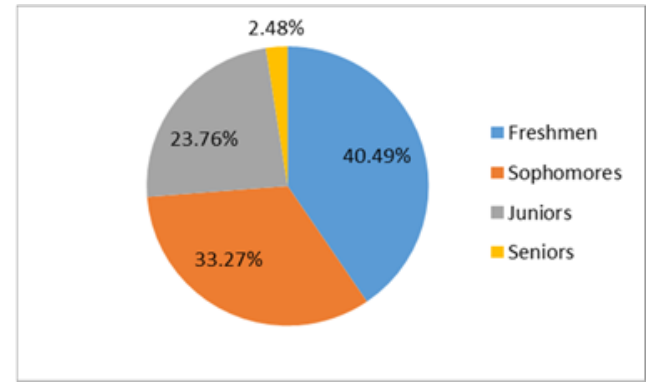

Figure 1 Number of students covered in various grades.

In the survey of students' daily learning time through online teaching, $5.1 \%$ of students learn within 2 hours, $22.56 \%$ learn within 2-4 hours, $44.56 \%$ learn within 4-6 hours, and $27.78 \%$ learn more than 6 hours. This shows that most of the time students spend on online learning through online teaching is 4-6 hours, indicating that the daily curriculum is also the same as the offline time.

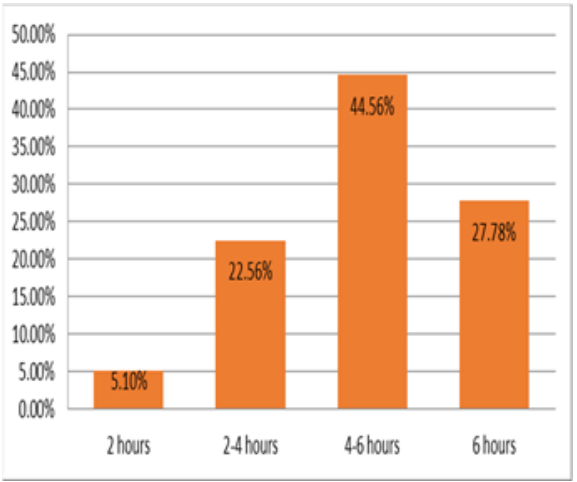

Figure 2 The length of students' online learning.

\subsection{Students' Understanding and Recognition of Online Teaching}

When it comes to students' understanding of online teaching before this semester, $39.57 \%$ of the students said they had already known about online teaching before, but they did not know much about it; 51.25\% of the students said they had experienced online teaching before, and they had experienced it more frequently; only $2.83 \%$ of the students had heard about it but had not used it, and $6.35 \%$ of the students had never heard of it. Thus, it seems that the students had experience with online teaching before the school launched online teaching, which also facilitated them to quickly understand the online teaching methods and adapt to the online teaching mode relatively quickly. In the background of the Internet era, college students have participated in school platforms such as Mooc and XuetangX etc, so they are not unfamiliar with online teaching and already have a lot of experience in attending classes.

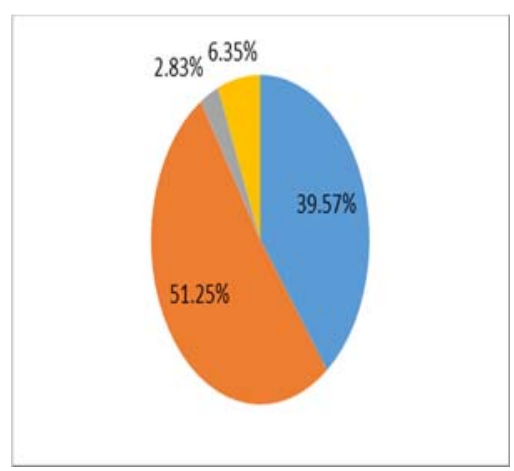

Figure 3 Students' understanding and recognition of online teaching.

When it comes to whether online teaching contributes to the communication and discussion with 
teachers and students, $7.6 \%$ of students think it is very helpful, $42.74 \%$ think it is helpful, $39.23 \%$ think it is similar to the effect of teaching at school, $9.86 \%$ think it is not helpful, and the remaining $0.57 \%$ say they are not sure. Students can communicate with teachers face-to-face by asking questions in the classroom, and they can communicate with teachers through bullet comments and videos in the online teaching project. It can be seen that the ratio of students who think that online teaching is helpful for communication between teachers and students and those who think that the effect is similar to that of teaching in school is basically equal. There is no face-to-face traditional classroom, but the point-to-point communication and interaction between teachers and students is increased, so the overall communication and interaction effect between teachers and students still has some room for improvement, and teachers can further optimize the teaching design to improve the interaction efficiency.

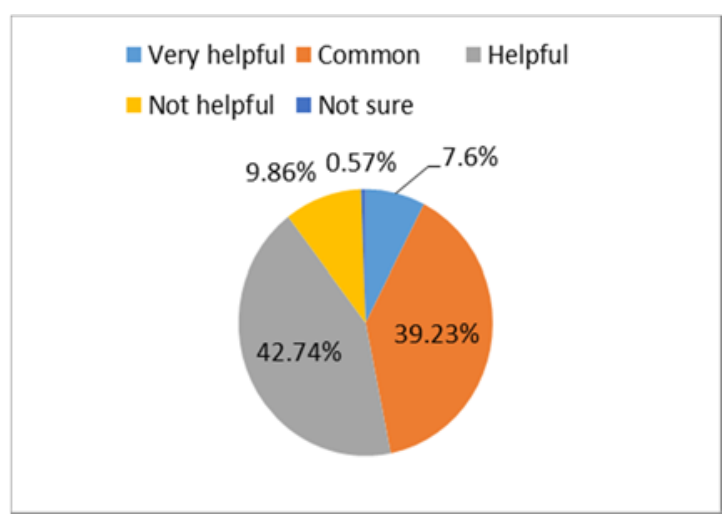

Figure 4 Whether online teaching contributes to the communication and discussion between teachers and students.

When it comes to whether online teaching contributes to students' learning progress, $5.1 \%$ of students said it is very helpful; $64.29 \%$ said it is somewhat helpful, and $20.63 \%$ said it is not effective; $5.1 \%$ and $4.88 \%$ of students said it is an obstacle and unclear respectively. The analysis shows that more than half of the students think that online teaching is helpful to their own learning progress and recognize that such a form of teaching improves the self-learning management and can achieve certain results. However, some students think that online teaching is not binding for students with poor self-discipline, which leads to students not being able to keep up with the pace and not submitting assignments on time. It also shows that there is still room for further improvement of students' learning outcomes in online teaching.

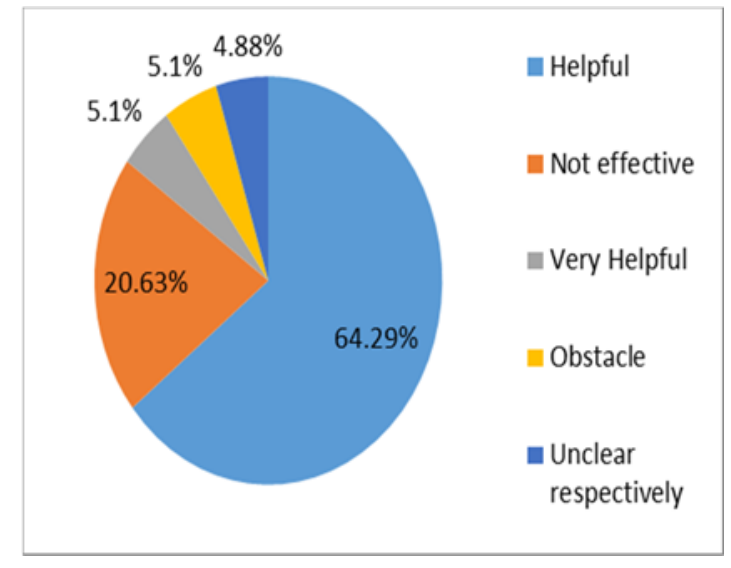

Figure 5 Whether it contributes to students' learning progress.

When it comes to the frequency of students' use of various functions of online teaching, the push of courseware of PPT and the bullet comments of PPT are the two options most chosen by students. $68.82 \%$ of the students said they often use the push of courseware of PPT, and $80.5 \%$ of the students said they often use the bullet comments of PPT. Among the functions that students barely use, $63.95 \%$ of students said that the function of class red pocket has almost not been used, $32.31 \%$ of the students said that they barely use the function of not understanding the PPT. It can be seen that students only use the common functions of online teaching, and teachers do not make full use of other functions for online teaching. In fact, the features of online teaching include questioning mode when the courseware is being made and pre-review mode before and after class, but these features have not been widely used.

\subsection{Students' Feelings and Feedback on Online Teaching}

In the survey, $4.76 \%$ of the students said that online teaching had increased their interest in learning, $45.69 \%$ said that it had increased their interest to some extent, $35.37 \%$ said that it had not increased their interest, 8.62\% and $5.5 \%$ said that online teaching had the opposite effect or they were not sure whether it had increased their interest in online learning. This comprehensive online teaching allows students to be exposed to this new way of learning to varying degrees, and to a certain extent, attracts students' attention and stimulates their interest in learning. 


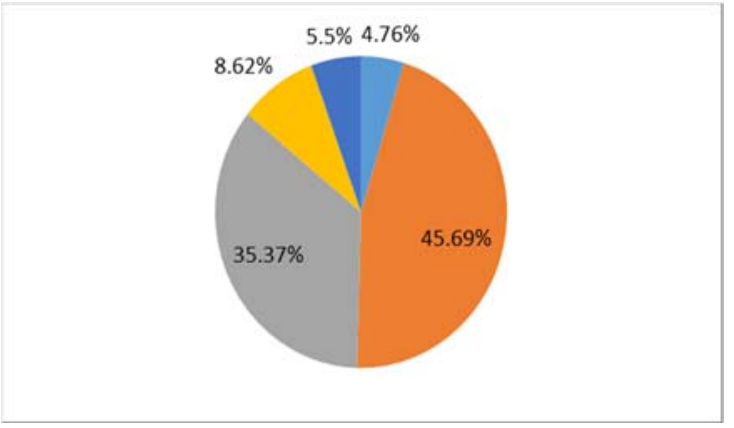

Figure 6. Whether it has increased the interest in online learning.

When there are questions in the research about how students feel when using online teaching, 9.52\% of students said they feel very relaxed; $59.25 \%$ said they feel relaxed; $16.67 \%$ said they feel nervous; while $3.97 \%$ said they are very nervous; and the remaining $10.54 \%$ said they are not too sure. As time goes by, students gradually get used to the online teaching and become more and more comfortable with this learning method, so most of them feel relaxed about the online teaching and do not feel as nervous as they did at the beginning.

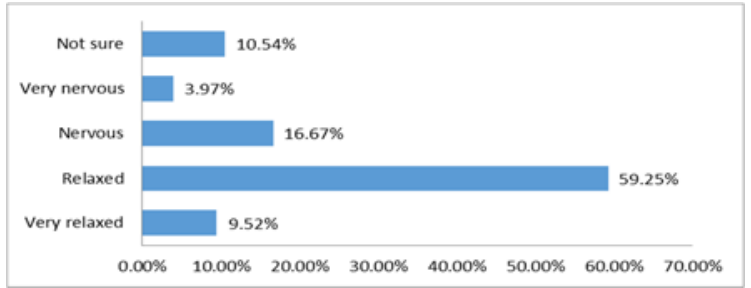

Figure 7 Psychological feelings when using online teaching.

When investigating the problems students encountered in the process of using online teaching (multiple choice), $47.85 \%$ of them chose that they could only hear the teacher's voice unilaterally, and the students could not communicate with the teacher in real time; $51.13 \%$ of them thought that the message notification of online teaching was not timely and they were often late for class; $21.77 \%$ of them said that the bullet comments sent in online teaching could not use a real-name system, and they could not know each other's identity, which was an obstacle to learning and communication; and the remaining $16.67 \%$ had other problems. Therefore, there is a need to shift from "being teacher-centered" to "being student-centered", from focusing on "what the teacher has taught" to focusing more on "what the students have learned".

\section{PROBLEMS AND DIFFICULTIES OF ONLINE TEACHING}

Based on the results of the questionnaire survey and the two main categories of the current main modes of online teaching, this study analyzes the existing problems.

\subsection{Analysis of the Problems of the Questionnaire Results}

\subsubsection{It is Difficult for Teachers and Students to Communicate and Interact with Each Other}

Through the research, it can be found that a major drawback of online teaching is that only the voice of the teacher can be connected unilaterally but not that of the student, forming information asymmetry. Teachers cannot know what students think in real time, and it is difficult for students to communicate and interact with teachers, so they can only express their thoughts by sending bullet comments. But by the time students send out the bullet comments, the teacher has already finished talking about this knowledge point and moved on to the next one, thus making it much more difficult for teachers and students to communicate with each other.

\subsubsection{The Functions of Online Teaching are not Fully Utilized.}

For most teachers and students, it is the first time that online teaching is widely used in the classroom. Even before this, some teachers and students have used online teaching, but only as an auxiliary tool to introduce it into the classroom, and only know the common functions such as showing PPT and sending bullet comments in online teaching. They have not seriously explored other functions, thus ignoring other functions that are helpful to online teaching. It fails to give full play to its potential functions, so that the online teaching does not achieve the expected effect.

\subsubsection{Some of the Drawbacks of Online Teaching Dampen the Enthusiasm of Teachers and Students}

The development and application of a software platform will naturally have shortcomings when it brings convenience to the development of learning life, and so does online teaching, such as poor stability, easy to crash, frequent network lag, and the fact that teachers 
and students can not communicate in real time. In addition, teachers and students are just starting to use online teaching, and they are not yet proficient in operation, so when they encounter some unexpected problems, they are often confused and do not know how to deal with them. As time goes by, their enthusiasm for online teaching is easily dampened.

\subsection{The Current Main Online Teaching Mode}

\subsubsection{Online Course}

Online courses are the combination of teaching content and implementation of teaching activities of a subject represented through the Internet. The disadvantage of online courses is that teachers cannot keep track of students' learning in real time, and students' learning largely depends on students' self-discipline. At the same time, online courses are based on videos of students' independent study, reading materials, and exercises, which make it difficult to test students' learning effects and lack a good learning atmosphere at the same time.

\subsubsection{Online Live Broadcasting Teaching}

Online live broadcasting teaching is the live teaching activity of teachers through online media. The main disadvantage of online live streaming is the problem of network instability caused by too many people learning online, and the instability of both the teacher's side and the student's side may arise in the process of online live broadcasting teaching.

\subsubsection{Student Independent Learning}

Independent learning means that students learn voluntarily by themselves under the tutor's remote guidance and using the available resources provided by the teacher, and have their own independent learning. The disadvantages of student independent learning and the disadvantages of online courses on the Internet are common in that student independent learning is more demanding for students, requires students to have a plan for the learning content, and the atmosphere of learning is poor.

\section{CONCLUSION}

\subsection{In Terms of Teachers}

\subsubsection{Improve the Regular Grades and Attendance System}

It is the update of teaching concept that triggers the change of teaching method, and the new technology and means will be applied to the teaching. Most of the students said that the teaching was conducted by online teaching, and the students' usual performance was mostly scored through the sign-in record of online teaching, which to a certain extent did not reflect the students' usual performance. It is suggested that teachers can use students' performance in class and after-school assignments, and then combine it with the sign-in records of online teaching to score the usual performance in certain proportion. In addition, students also said that when using online teaching, they were often forced to quit online teaching due to network lag or other uncontrollable factors, resulting in insufficient study hours or being recorded as absent in the backstage. It is suggested that teachers should record attendance according to the actual situation of the students, rather than scoring attendance based only on the backstage records of online teaching.

\subsubsection{Be Good at Discovering other Functions of Online Teaching to Enhance Students' sense of Participation in online Teaching}

Most of the students said that the only functions they often use in online teaching are PPT learning and sending bullet comments, but they do not know much about other functions of online teaching. It is suggested that teachers can explore other functions of online teaching, such as learning reports at the end of each lesson, real-time class quizzes, and pre-testing push, etc., so as to fully utilize these functions in the classroom and enhance students' sense of participation in online teaching.

\subsubsection{Combine Online Teaching with other Learning Platforms to guarantee the Quality of online Teaching}

Through the survey, students said that using online teaching for online teaching, they can only hear the teacher's voice and see the teaching PPT unilaterally, and students cannot interact with the teacher through 
online teaching. And the bullet comments sent in online teaching cannot use the real-name system, so both teachers and students cannot know each other's identity, which to a certain extent hinders the communication and learning between teachers and students. It is suggested that teachers can combine online teaching with other platforms for teaching, such as Tencent Meeting and QTalk etc, so that students can have more opportunities to join in the communication and discussion of online teaching, and guarantee the quality of students' online learning while promoting online teaching in an orderly manner.

\subsubsection{Be a Good Supporter of Students' learning and Help them Make Good Online Learning Plans}

Because the teacher can not supervise the students' learning in online teaching, the teacher can designate learning tasks at certain time points, so as to supervise the students' online learning. At the same time, teachers should support students' online learning, and can arrange regular Q\&A according to students' learning situation, while setting up class learning assistants to regularly collect the problems encountered by students in online learning to promote the formation of a good learning atmosphere.

\subsection{In Terms of Students}

\subsubsection{Be Clear about the Learning Tasks and Adapt to the Online Teaching Mode as soon as Possible}

For most students, it is the first time to have online teaching. Some students fail to come out from the holidays and the previous offline teaching mode, and they do not pay high attention to online teaching, or even treat it negatively, resulting in falling behind in certain courses. It is recommended that students change their previous attitude, adjust themselves, put their energy into online teaching, adapt to the online teaching mode as soon as possible, study hard to learn knowledge, and make up for the lessons they missed before.

\subsubsection{Strengthen the Communication with Teachers}

With the online teaching, although students can't connect with the teacher for real-time communication, they can ask questions to the teacher through the function of not understanding, or contact the teacher in class to solve their questions. It is recommended that students take full advantage of the speed and convenience of the Internet to enhance their communication with the teacher. Students should take the initiative to communicate with teachers in the online teaching, give feedback to teachers on their learning situation and learning trajectory, and help teachers collect students' opinions and suggestions in multiple ways and give feedback in a timely manner to help teachers improve the quality of online teaching.

\subsubsection{Pay Attention to the News of Online Teaching in Time and Do a Good Job of Preview and Reviewing}

Some students say they don't pay much attention to the online teaching news, so they often miss class time and forget to finish their homework after class. Therefore, it is recommended that students pay attention to the news sent by teachers through online teaching, check the class schedule every day to know the course and time slot of the day, and attend classes on time. In addition, by teaching online through online teaching, students can preview the course content and review what they have learned before to consolidate the knowledge acquired and enhance their understanding.

\section{REFERENCES}

[1] Department of Higher Education, Ministry of Education. (2020). Information on online education in higher education and considerations for next steps (2020-05-14). Retrieved from http://www.moe.gov.cn/fbh/live/2020/51987/sfcl/20 2005/t20200514_454117.html

[2] Xie Huomu, Liu Lichun, Chen Yi'an. Reflections on online teaching in universities in the context of the epidemic [J]. China University Teaching, 2020,357(05):59-62.

[3] Zeng Liwen. Analysis of the effect of the implementation and influencing factors of online teaching in the context of epidemic prevention and control--a survey based on universities in Guangdong Province[J]. Exploration of Higher Education,2020.7: 87-93.

[4] Fang Lin. The current situation, problems and embedding path of "online teaching" in colleges and universities [J]. Market Research, 2018(12):15-17.

[5] Jiao Jianli, Zhou Xiaoqing, Chen Zexuan. A case study of online teaching in the context of epidemic prevention and control [J]. China audiovisual education, 2020(3): 106-113. 